\title{
Ambiente flúvio-deltáico influenciado por maré e tempestade da Formação Rio Maria, leste da Província Carajás (SE) do Cráton Amazônico
}

\author{
Marivaldo dos Santos Nascimento ${ }^{1 *}$, Camila Vilar de Oliveira ${ }^{1}$, Fernando J. Althoff $^{2}$
}

\begin{abstract}
Resumo A Formação Rio Maria compreende uma sucessão sedimentar progradante depositada em mar epicontinental desenvolvido ao longo da borda leste da Província Carajás - a mais antiga província do Cráton Amazônico - tendo sido intrudida por granitos em torno de $1.88 \mathrm{Ga}$. Quatro associações de fácies foram reconhecidas: prodelta-barras distais, frente deltaica-shoreface, planície deltaica-distributários e canais fluviais. Estratificações cruzadas hummocky e swaley de grande porte ( $>1 \mathrm{~m}$ ) atestam influência de ondas de tempestade nos depósitos de shoreface (tempestitos) e estratificações bipolares com recobrimento argiloso indicam atuação de processos de maré. As composições modais dos componentes detríticos do quartzarenito, sublitarenito e arcóseo indicam fontes de blocos continentais (Cráton interior, segundo a classificação de Dickinson). Os minerais pesados (por exemplo, zircão, turmalina, estaurolita, epidoto, etc.) sugerem contribuições de rochas plutônicas félsicas e metamórfica. Grãos de zircão muito bem arredondados podem ser relacionados a sedimentos reciclados ou intensamente retrabalhados, ou fontes metamórficas. Esses litotipos podem ser atribuídos às rochas que constituem o Bloco Rio Maria, que inclui granitos e rochas metamórficas do terreno granitogreenstone de Rio Maria $(3.0-2.86 \mathrm{Ga})$.
\end{abstract}

Palavras-chave: depósitos de maré; estratificação cruzada hummocky; Formação Rio Maria; Cráton Amazônico.

\begin{abstract}
Fluvial-deltaic depositional environment influenced by tide and storm of The Rio Maria Formation, east of Carajás Province, Amazonian Craton. The Rio Maria Formation is a siliciclastic sedimentary sequence deposited in an eiperic sea formed along of eastern edge of the Carajás Province - the oldest Archean province of the Amazonian Craton being intruded by rapakivi-type granite $(1.88 \mathrm{Ga})$. Four facies associations have been recognized: prodelta-distal bar, delta-front/shoreface, delta-plain/distributaries and fluvial channels. Large-scale hummocky-swaley cross-stratifications $(>1 \mathrm{~m})$ attest storm waves-influenced in upper shoreface deposits (tempestites). Bipolar cross-beddings with drape and reactivation surfaces reflect tidal-influence. Quartzarenite, sublitharenite and subarkose modal frameworks indicate stable continental block (craton interior) source. Heavy-minerals assemblages (e.g. zircon, tourmaline, staurolite, epidote, etc.) provide evidence of contribution from felsic plutonic igneous and metamorphic rocks. Well-rounded zircon grains can be associated to reworked sediments or metamorphic sources. These litotypes can be related to Rio Maria Block, which includes granitoid and metassedimentary rocks of the Rio Maria granite-greenstone terrain (3.0 - 2,86 Ga).
\end{abstract}

Keywords: tide deposits; hummocky cross-stratification; Rio Maria Formation; Amazonian Craton.

INTRODUÇÃO Rochas sedimentares pré-cambrianas são componentes litoestratigráficos relevantes do Cráton Amazônico, o mais importante núcleo geotectônico da Plataforma Sul-America (Almeida 1967, 1978) (Fig. 1A). Essas rochas representam ambientes de sedimentação formados em contexto paleogeográfico ainda muito pouco estudados, embora importantes para a compreensão da origem e evolução de bacias sedimentares pré-cambrianas da Província Mineral de Carajás, onde as coberturas siliciclásticas encontram-se preservadas na Serra de Carajás (Grupo Rio Fresco) e no Sinclinório de Rio Maria (Grupo Gemaque), onde as exposições revelam estruturas primárias muito bem preservadas que permitem reconstituir seus ambientes deposicionais.

As rochas sedimentares estudadas neste trabalho encontram-se dispostas na borda leste da Província Amazônia Central (Província Carajás) (Fig. 1B), estando em não conformidade com o terreno granito-greenstone de Rio Maria, em uma área de aproximadamente $400 \mathrm{~km}^{2}$, a leste da cidade de Rio Maria (Fig. 1C). Essas rochas têm sido correlacionadas, segundo DOCEGEO (1988) e Huhn et al. (1988), à Formação Águas Claras (Grupo Rio Fresco). Contudo, a compreensão da evolução sedimentar dessas rochas, bem como a sua relação estratigráfica

\footnotetext{
${ }^{1}$ Faculdade de Geologia, Campus Universitário de Marabá, Universidade Federal do Pará - UFPA, Marabá (PA), Brasil.

E-mails:msn@ufpa.br,kmilaviol@hotmail.com

${ }^{2}$ Centro de Filosofia e Ciências Humanas, Departamento de Geociências, Universidade Federal de Santa Catarina - UFSC,

Florianópolis (SC), Brasil. E-mail: althoff@gmail.com

*Autor correspondente
} 
com outras unidades estratigráficas adjacentes, ainda necessita de estudos detalhados. Neste contexto, o presente trabalho apresenta a análise faciológica e a caracterização petrográfica das rochas sedimentares do Sinclinório de Rio Maria, tendo em vista a reconstrução peleoambiental desses depósitos, sob a ótica dos trabalhos de Eriksson et al. (2004), Miall (2006) e Catuneanu (2006).

CONTEXTO GEOLÓGICO O Cráton Amazônico constitui-se em terrenos arqueanos e paleoproterozoicos individualizados na forma de seis províncias geocronológicas (Tassinari \& Macambira 1999): Amazônia Central ( $>$ 2,5 Ga), Maroni-Itacaiúnas $(2,2$ - 1,95 Ga), Ventuari-Tapajós $(1,95-1,8 \mathrm{Ga})$, Rio Negro-Juruena (1,8 - 1,55 Ga), RondonianaSão Ignacio (1,5 - 1,3 Ga) e Sunsás $(1,25-1,0 \mathrm{Ga})$ (Fig. 1B). A Província Amazônia Central tem sido amplamente estudada devido às ocorrências de reservas de minérios de ferro, cobre, níquel, manganês, etc., e encontra-se subdividida em dois domínios ou blocos tectônicos: Carajás e Rio Maria.

O Bloco Carajás limita-se com a Província Maroni-Itacaiúnas, ao norte, e com a Faixa Araguaia, a leste, sendo formado por rochas arqueanas dos complexos Luanga, Estrela, Serra do Rabo e Old Salobo, além de metavulcanossedimentares da Bacia de Carajás (Supergrupo Itacaiúnas), Formação Águas Claras e Gorotire, intrudidas por granitos anorogênicos paleoproterozoicos da Suíte Carajás. As porções sul e oeste desse bloco encontram-se parcialmente recobertas por sequências sedimentares fanerozoicas (Bacia de Parecis e vulcânicas paleoproterozoicas do Grupo Iriri).

OBloco Rio Maria destacado na Figura $1 \mathrm{C}$ compreende terrenos arqueanos constituídos por extensas faixas de greenstone do Supergrupo Andorinhas (2,98 Ga: Avelar 1996), além de tonalitos-trondhjemitos de
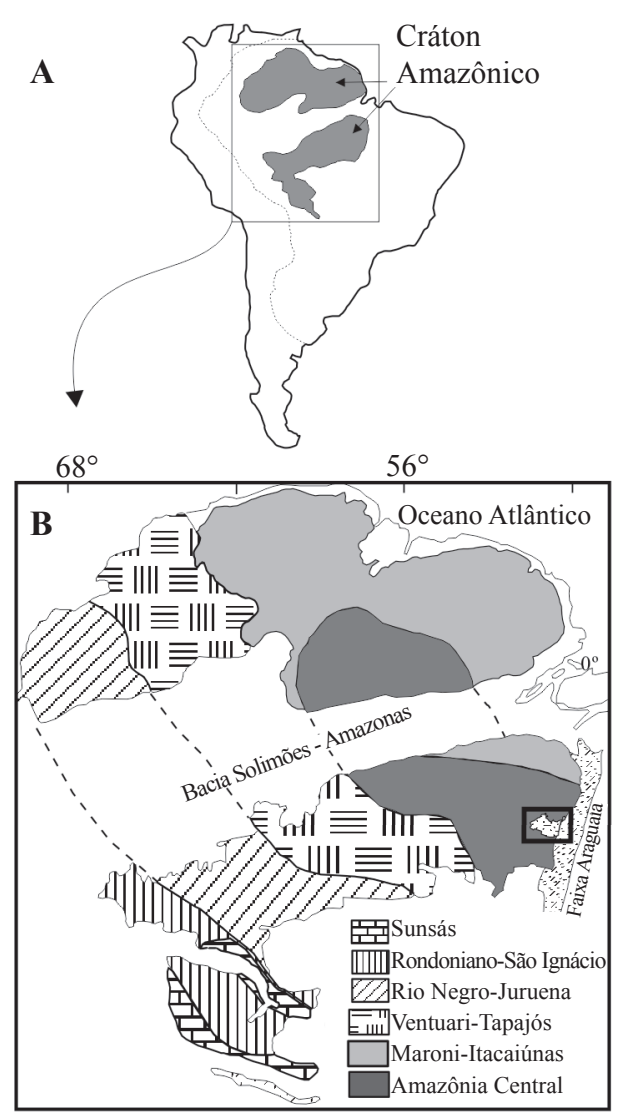

Arqueano

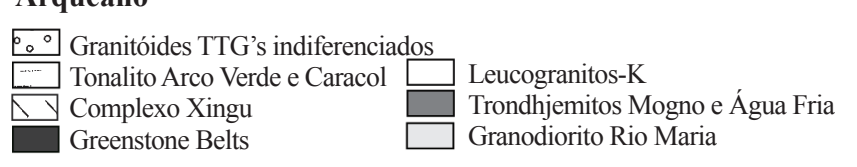

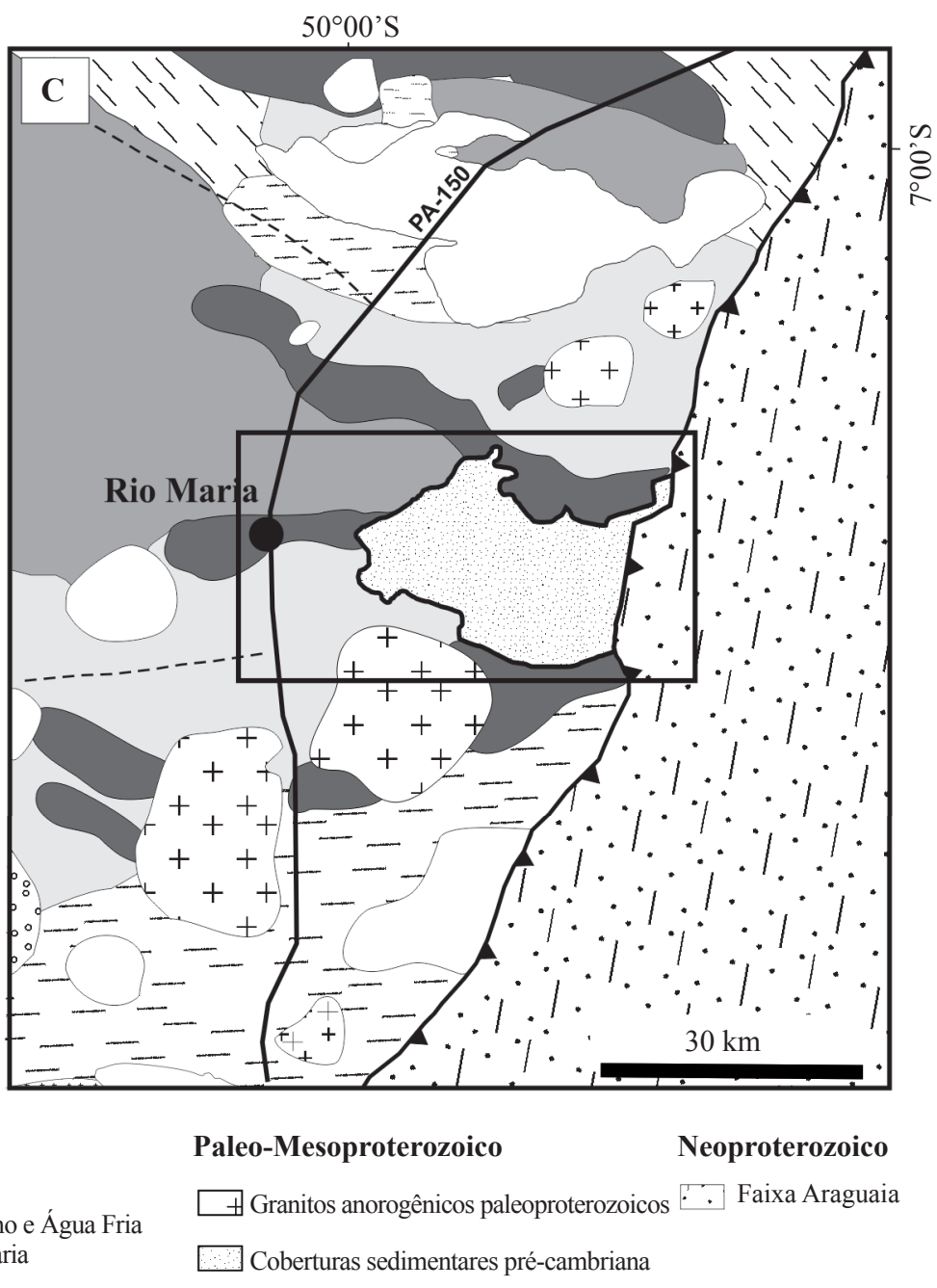

Figura 1-(A) O Cráton Amazônico na Plataforma Sul-Americana; (B) províncias geocronológicas do Cráton Amazônico (modificado de Tassinari \& Macambira 1999); e (C) Sinclinório de Rio Maria. 
2,98 e 2,86 Ga (Macambira 1992, Dall'Agnol et al. 1994, Sardinha 2002, Leite et al. 2004) e granitoides de 2,87 Ga (Macambira \& Lancelot 1991). Sobre essas unidades arqueanas estão dispostas, discordantemente, a Formação Rio Maria, estudada neste trabalho, mas referenciada em trabalhos anteriores como Grupo Gemaque (DOCEGEO 1988). Granitos anorogênicos das suítes Jamon e Musa de 1,88 Ga (Oliveira 2006, Ferreira et al. 2008) são intrusivos nas sequências sedimentares (estudadas neste traba1ho) e no embasamento arqueano (Fig. 2).

No limite leste do Sinclinório de Rio Maria, ocorre a Faixa Araguaia, cinturão orogênico neoproterozoico formado pelo Supergrupo Araguaia, constituído por metaconglomerados, quartzitos, micaxistos e xistos ricos em granada, estaurolita e cianita (Formação Morro do Campo), além de xistos, metarenitos e metacalcários (formações Pequizeiro e Couto Magalhães) dos Grupos Estrondo e Tocantins (Fig. 2), e granitos de $655 \mathrm{Ma}$ (Moura \& Gaudette 1999). Os Complexos Colméia (2,85 - 2,86 Ga) e Gnaisse Cantão (1,85 Ga) representam parte do Cráton Amazônico (Moura \& Gaudette 1999) deste cinturão.

TRABALHOS ANTERIORES Os primeiros estudos sobre as coberturas pré-cambrianas da Província Mineral de Carajás foram realizados por Oliveira (1928), reportando-se às camadas com carvão na bacia do Rio Fresco. Barbosa et al. (1966) denominaram esses depósitos de Formação Rio Fresco, cuja seção-tipo foi definida no baixo e médio curso do rio homônimo. Silva et al. (1974) estenderam a denominação "Formação Rio Fresco" para toda as rochas sedimentares de Carajás, porção basal do Grupo Uatumã. A Formação Rio Fresco passou a ser tratada como dois membros: o Membro Azul (inferior), que aflora na margem direita do rio Itacaiúnas (Serra dos Carajás) e inclui conglomerados, arenitos e folhelhos manganesíferos e carbonosos; e o Membro Naja (superior), definido na margem direita do Rio Fresco (Serra da Tocandera) que inclui arcóseos, siltitos, grauvacas, ardósias, rochas carbonosas e calcíferas. Marinho et al. (1977) mantiveram a subdivisão da Formação Rio Fresco em dois membros, porém limitaram-se informalmente em denominá-los membro inferior e membro superior, destacando contato gradacional entre eles. Cunha et al. (1984) elevaram a Formação Rio Fresco à categoria de "Grupo", posicionando-o no Proterozoico médio e subdividindo-o nas formações Igarapé Azul (inferior) e Rio Naja (superior).
Cordeiro \& Saueressig (1980) e Cordeiro (1982), em seus trabalhos sobre os sedimentos clásticos-químicos discordantes aos greenstone belts do Supergrupo Andorinhas, usaram o termo Sequência Gemaque para se referirem às "rochas com metamorfismo incipiente" expostas em um sinclinório aberto para leste, incluindo-as na Formação Rio Fresco de Barbosa et al. (1966). DOCEGEO (1988) admite uma única bacia para toda a sedimentação pré-cambriana do sul do Pará, tendo como referência os testemunhos preservados na forma de 'sinclinais abertas'. Dessa forma, adotou-se a definição de Grupo Rio Fresco, como proposto por Cunha et al. (1984), com a mesma abrangência de Silva et al. (1974). Santos \& Pena Filho (2000) se referem às rochas sedimentares da então Serra das Andorinhas como Grupo Gemaque, portanto desmembrando-as do Grupo Rio Fresco e subdividindo-as em Formação São Roque e Cachoerinha, embora apenas com base em critérios litoestratigráficos.

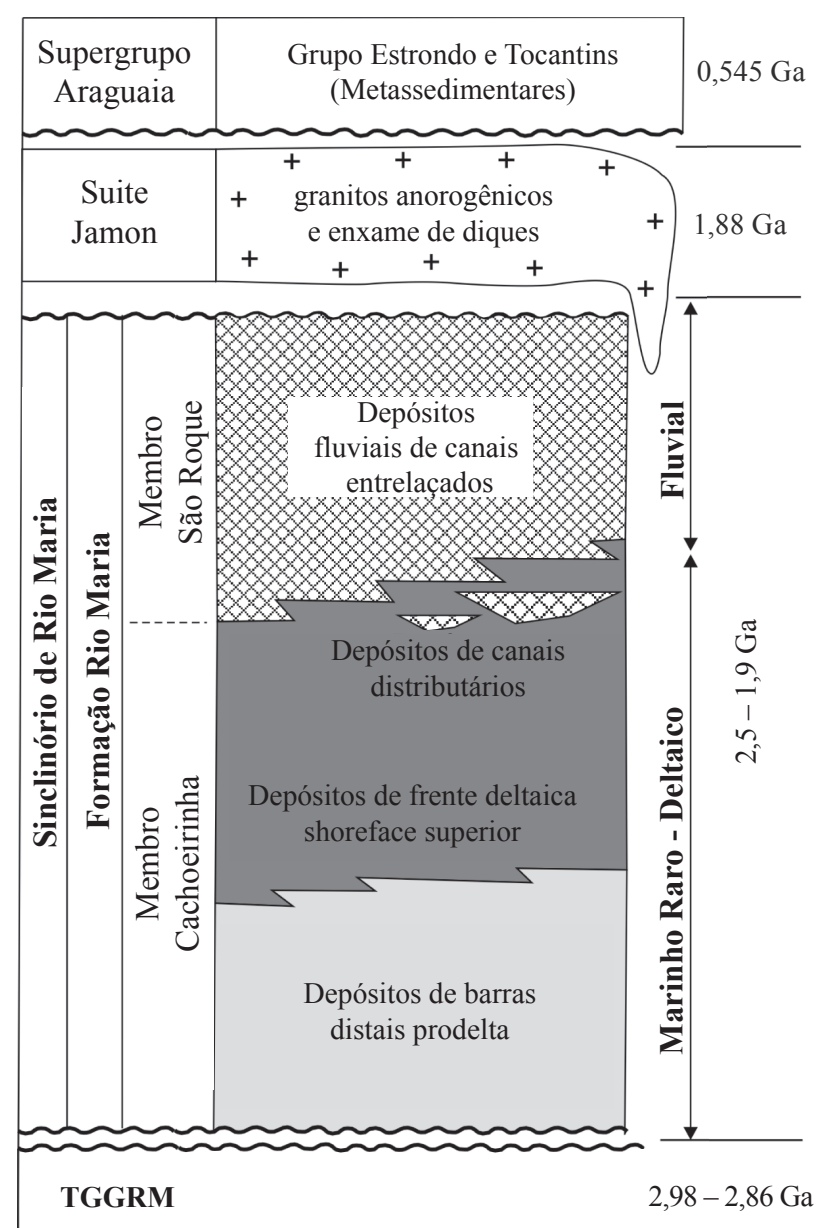

Figura 2 - Contexto estratigráfico da Formação Rio Maria no Terreno Granito-Greenstone de Rio Maria (TGGRM), intrudida pela Suite Intrusiva Jamon. 
A Formação São Roque tem sido considerada a porção basal e a Formação Cachoerinha o topo do Grupo Gemaque, e ambas incluem arenitos, siltitos, conglomerados e raros pelitos de ambiente flúvio-marinho raso, planície de inundação, leques aluviais e lago costeiro (DOCEGEO 1988). Baseado na correlação com o Grupo Rio Fresco e deste com a Formação Águas Claras, essas rochas foram posicionadas no Neoarqueano (Mougeot et al. 1996, Dias et al. 1996). Santos et al. (2003) e Faraco et al. (2004b) posicionam esse grupo no Arqueano. Macambira (1992), com base em idades de zircão detrítico, estabelece uma idade máxima de sedimentação de $2,76 \mathrm{Ga}$. Finalmente, a CPRM (2008) considera que as rochas sedimentares dos grupos Rio Fresco e Gemaque são segmentos de uma única bacia plataformal, referida como Bacia do Rio Fresco e, assim, o Grupo Gemaque passou a ter idade paleoproterozoica.

Novos dados estratigráficos e sedimentológicos levantados neste trabalho comprovam que, na ausência de superfícies com conotação estratigráfica, essas formações podem ser consideradas geneticamente relacionadas e, portanto, pertencentes a uma única sequência deposicional (Fig. 2). Propondose o rebaixamento da categoria Formação para Membro, as unidades litoestratigráficas São Roque e Cachoeirinha, que juntas compõem a Formação Rio Maria, que por sua vez toma o lugar do Grupo Gemaque, as descrições a seguir serão referenciadas como Membros São Roque e Cachoeirinha, e Formação Rio Maria (Figs. 2 e 3). O Membro Cachoeirinha corresponde à base e à sequência intermediária da Formação Rio Maria, sendo constituído de fácies pelíticas depositadas em ambiente de barras distais-prodelta, que gradam lateral e verticalmente para siltitos e arenitos de frente deltaica-shoreface, planície deltaica braided-distributários. O Membro São Roque ocorre na porção superior e é formado por arenitos médios a grossos de canais fluviais entrelaçados.

\section{RESULTADOS}

Associações de fácies As fácies sedimentares descritas neste trabalho compreendem 28 afloramentos dispostos no flanco norte e na porção central do Sinclinório de Rio Maria (Fig. 3), cujos perfis estratigráficos foram levantados diretamente no campo em uma escala de mapeamento de 1:25.000, mediante caminhamento e medição da espessura dos pacotes sedimentares com trenas para representação gráfica da sucessão das camadas e das fácies. Os afloramentos apresentam, às vezes, suaves basculamentos (variando de 5 a $20^{\circ}$ ) e boa continuidade lateral que permitiu a construção de seções panorâmicas para visualização da geometria dos corpos sedimentares.

As fácies foram agrupadas de acordo com os litotipos principais que incluem essencialmente arenitos quartzosos e pelitos. Em alguns locais, foi possível elaborar seções verticais até o topo da aba do Sinclinório de Rio Maria, facilitando a análise detalhada dos contatos sedimentares e do padrão de sucessão das litofácies. A forma das camadas foi documentada a partir da confecção de fotomosaicos elaborados com imagens de câmeras fotográficas. Na ténica utilizada para interpretação da sucessão vertical de fácies, as superfícies estratigráficas foram entendidas como possíveis limites entre as fácies ou associações de fácies, não existindo uma preocupação adicional como o seu intrincado arranjo lateral, uma vez que os afloramentos nem sempre apresentaram continuidade física entre si. A partir do estudo dos afloramentos e dos perfis correspondentes, foi possível elaborar um perfil estratigráfico composto por estes cerca de $40 \mathrm{~m}$ de espessura, constituído da base para o topo em quatro associações de fácies (Af): $A f 1, A f 2, \mathrm{~A} f 3$ e $A f 4$, em ordem estratigráfica ascendente (Fig. 4).

ASSOCIAÇÃO AfI Ocorre na porção mais inferior da sucessão sedimentar e inclui seis fácies sedimentares $P l, S l, P o, P m, S c$ e So, que são caracterizadas pelo predomínio de pelitos que gradam para o topo para arenitos muito finos, às vezes formando intercalações heterolíticas (Fig. 4: $A f 1$ ). A sucessão das camadas exibe um padrão de granocrescência ascendente com nítido espessamento das camadas de arenito muito fino para o topo (Fig. 5). As fácies $P l$ e $S l$ formam pacotes de pelitos e arenitos muito finos intercalados, geralmente, tabulares com ampla continuidade lateral $(>100 \mathrm{~m})$ e espessura que varia de 3 a $4 \mathrm{~m}$ (Fig. 5A). A fácies $P o$ compreende pelitos na forma de camadas levemente onduladas internamente com laminações plano-paralelo (Fig. 5B). A fácies $\mathrm{Pm}$ caracteriza camadas de pelito maciço lateralmente contínuas $(>50 \mathrm{~m})$ com espessuras que variam até poucos centímetros $(\sim 10 \mathrm{~cm})$. A fácies $S c$ é formada por pacotes de arenitos muito finos com laminações convolutas de pequeno porte, além de laminações plano-paralelas e quasi-planares (Fig. 5C). Esses pacotes sedimentares exibem contatos inferiores abruptos 


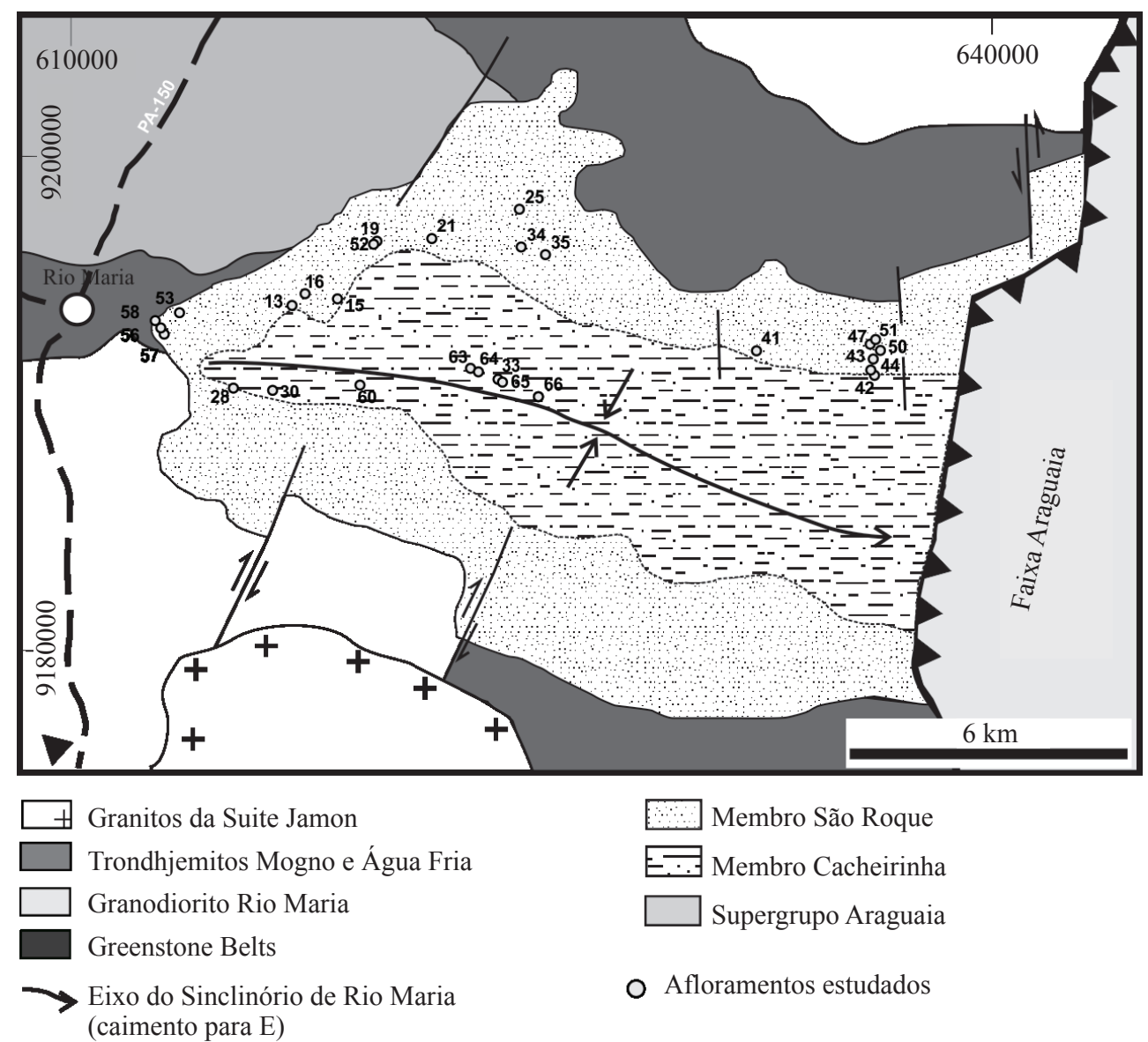

Figura 3 - Mapa geológico simplificado do Sinclinório de Rio Maria no leste do Terreno Granito-Greenstones de Rio Maria, com a localização dos aforamentos estudados.

ou erosivos, com cerca de $30 \mathrm{~m}$ de extensão lateral e 20 a $40 \mathrm{~cm}$ de espessura. A fácies So é composta de laminações truncadas que exibem convexidade para cima e se encontram associadas a feições rasas de erosão, ressaltadas na base por marcas onduladas simétricas e assimétricas.

Interpretação: essa associação de fácies representa o ambiente deposicional de baixa energia onde a deposição se processou por suspensão, com esporádica influência de correntes de fundo (tração). Acamamentos lenticulares suavemente ondulados, com laminações onduladas truncadas indicam ação de fluxos de corrente de fundo no leito deposicional. O padrão da sucessão com granocrescência ascendente evidencia processo de progradação do ambiente deposicional em direção à bacia receptora.

\section{ASSOCIAÇÃO Af2 É formada pelas fácies $P p$,} Ao, Af, Hm e So representadas por arenitos finos a médios, bem selecionados, com esporádicas camadas de pelito maciço intercalados (Fig. 4: Af2). Os arenitos ocorrem na forma de camadas com forma sigmoidal, tabular ou lenticular, lateralmente contínuas $(>50 \mathrm{~m})$, com até $50 \mathrm{~cm}$ de espessura, internamente com gradação inversa, base irregular e erosiva, às vezes interdigitadas com lentes de pelitos (Fig. 6). As camadas de arenitos apresentam forma lobada com mais de $5 \mathrm{~m}$ de espessura por até $100 \mathrm{~m}$ de extensão lateral, compondo ciclos de granocrescência ascendente com espessamento para o topo. Internamente, exibem laminação cruzada cavalgante com recobrimento argiloso, marcas onduladas simétricas e assimétricas que na parte superior dos pacotes estão associadas a laminações plano-paralelas, suavemente onduladas, e laminações cruzadas. A estrutura mais proeminente nesses depósitos é estratificação cruzada do tipo hummocky e swaley de grande porte (Figs. 6A e B) que aumenta em espessura e amplitude para o topo. As fácies $A o$ e $A f$ são caracterizadas por estratificações cruzadas, de muito baixo ângulo, que gradam lateralmente para laminações quase plano-paralelas onduladas. A fácies $P p$ consta de pelitos e arenitos finos compondo acamamentos heterolíticos lenticular, ondulado e flaser. 


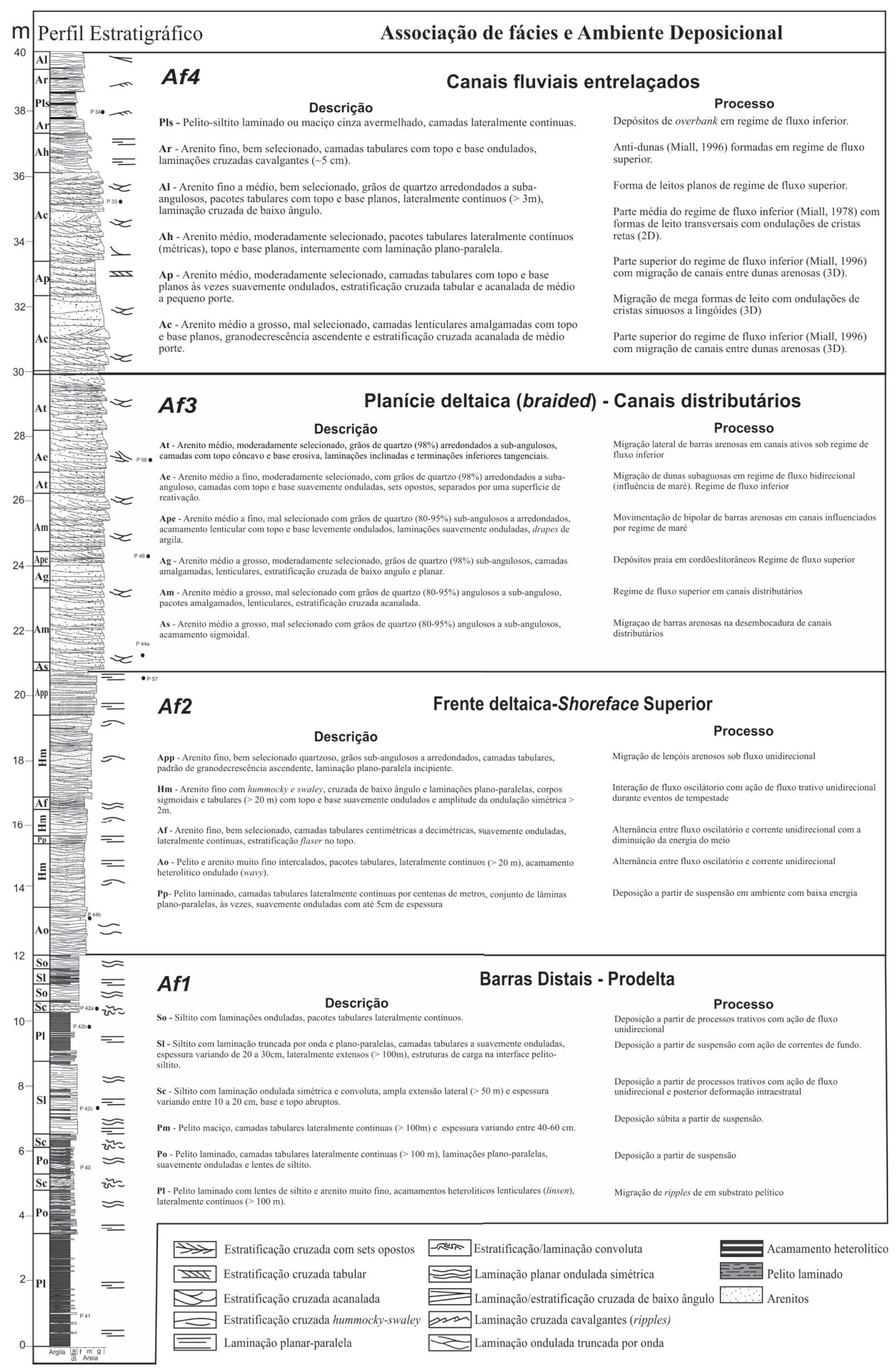

Figura 4 - Perfil estratigráfico composto para a Formação Rio Maria, contendo as fácies, associações de fácies, os respectivos ambientes de sedimentação e a posição das amostras para análise petrográfica. 


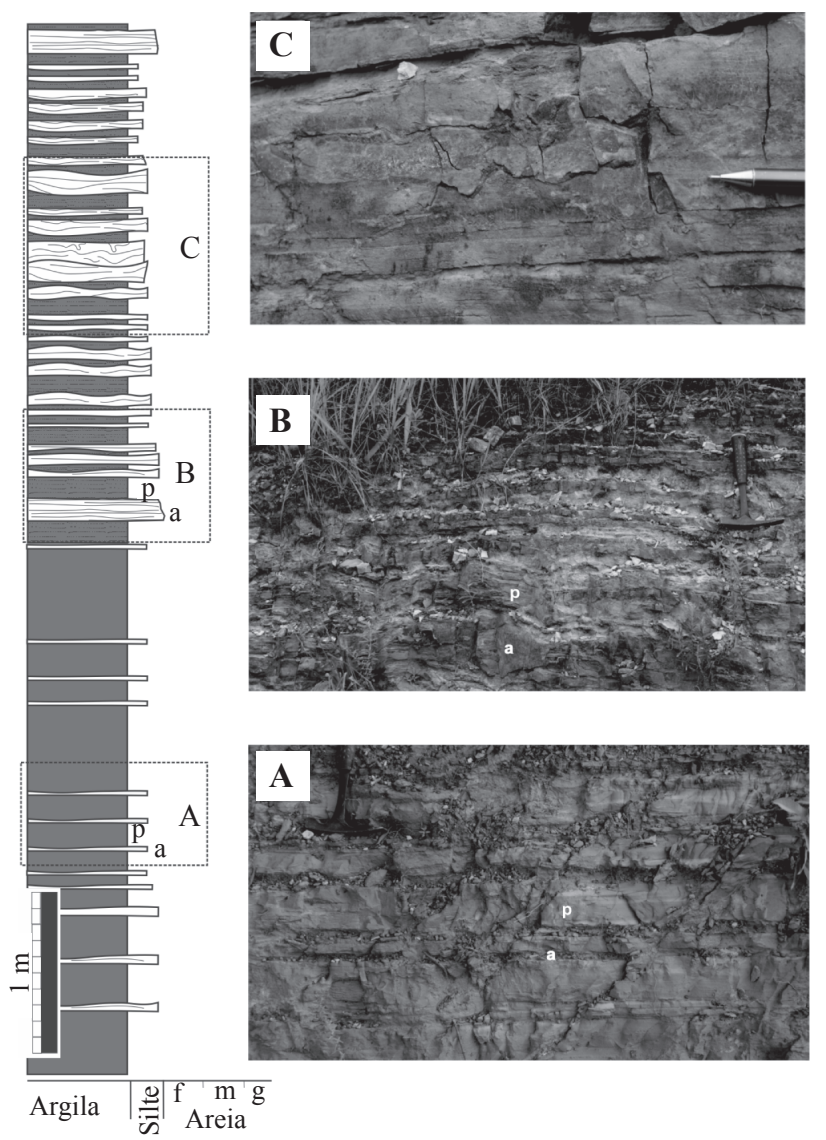

Figura 5 - Perfil litoestratigráfico da associação de fácies 1 (Af1): (A) pelito laminado (fácies Pl) com lentes de arenito muito fino maciço (fácies Pm); (B) intercalação siltito-pelito laminados; (C) siltito laminado com intercalação de lâminas de pelito. Notar o padrão de granocrescência ascendente da sucessão.

A fácies App é representada por arenitos finos, bem selecionados quartzosos, grãos subangulosos a arredondados, na forma de camadas tabulares, com padrão de granodecrescência ascendente e laminação plano-paralela (Fig. 6B).

Interpretação: esses depósitos foram acumulados sob a ação de ondas de tempestades. Fluxos combinados estão relacionados a ondas de tempestades que resultam da interação de fluxos oscilatórios com correntes geostróficas oblíquas ou perpendiculares à linha de costa (Duke et al. 1991, Cheel \& Lekie 1993). Nessas condições, a ação de tempestades e o retrabalhamento por correntes de deriva e retorno proporcionaram a formação de uma grande variedade de formas de leito, elevando a maturidade mineralógica e textural dos sedimentos. A presença de estratificações cruzadas do tipo hummocky e swaley (Figs. 6A e B), laminação quasi-planar atesta depósitos influenciados pela ação de ondas de tempestade de grande escala (Snedden \& Nummedal 1991, Walker \& Plint 1992). O predomínio de corpos arenosos amalgamados com essas estruturas sugere ambiente deposicional de fácies praial (shoreface) situado acima do nível de ação de ondas de tempo bom, que sofria constante ação de tempestades (Leckie \& Walker 1982). A diminuição progressiva da energia impulsiona a formação de acamamentos heterolíticos ( $f l a-$ ser, ondulado e lenticular), configurando depósitos que gradam de um caráter shoreface a offshore.

ASSOCIAÇÃOAf3 Ocorre logo acima dos depósitos de frente deltaica ( $A f 2$ ), sendo caracterizada por camadas de arenitos com ampla continuidade lateral (>100 m) e espessuras de 1 a $2 \mathrm{~m}$, tendo o topo e a base ondulados. Inclui as fácies $A s, A m, A g$, Ape, Ae e At (Fig. 4: $A f 3$ ) representadas por arenitos finos a médios, bem selecionados, com estratificação cruzada acanalada com sets $<0,5 \mathrm{~m}$ de espessura, formando camadas com 2 a $5 \mathrm{~m}$ de espessura, geralmente, de ocorrência restrita, formando canalizações rasas (Fig. 7A). Arenitos finos a médios, moderadamente a bem selecionados, ocorrem na forma de camadas com até $2 \mathrm{~m}$ de espessura, contendo base e topo erosivos; estratificação cruzada tabular com reativações (Fig. 7B), laminações cavalgantes e de baixo ângulo (Fig. 7C), estratificações cruzadas opostas (bipolares) com recobrimento de filmes argilosos (drapes) (Fig. 7D) e acanaladas com terminações tangenciais (Fig. 7E). Essas rochas têm relação lateral e vertical gradacional com os arenitos da frente deltaica. A fácies $A t$ inclui arenitos médios, moderadamente selecionados, grãos de quartzo (98\%) arredondados a subangulosos, na forma de camadas com topo côncavo e base erosiva, com laminações inclinadas e terminações inferiores tangenciais. A fácies $A e$ é representada por arenitos médios a finos, moderadamente selecionados, com grãos de quartzo arredondados a subangulosos, camadas com topo e base suavemente onduladas, sets opostos, separados por uma superfície de reativação. A fácies Ape é formada por arenito médio a fino, mal selecionado com grãos de quartzo subangulosos a arredondados, acamamento lenticular com topo e base levemente ondulados, laminações suavemente onduladas, com recobrimento argiloso. A fácies $A g$ é caracterizada por arenito médio a grosso, moderadamente selecionado, grãos de quartzo subangulosos, camadas amalgamadas, lenticulares, com estratificações cruzadas de baixo angulo e planar. A fácies $A m$ inclui arenitos médios a grossos, mal 

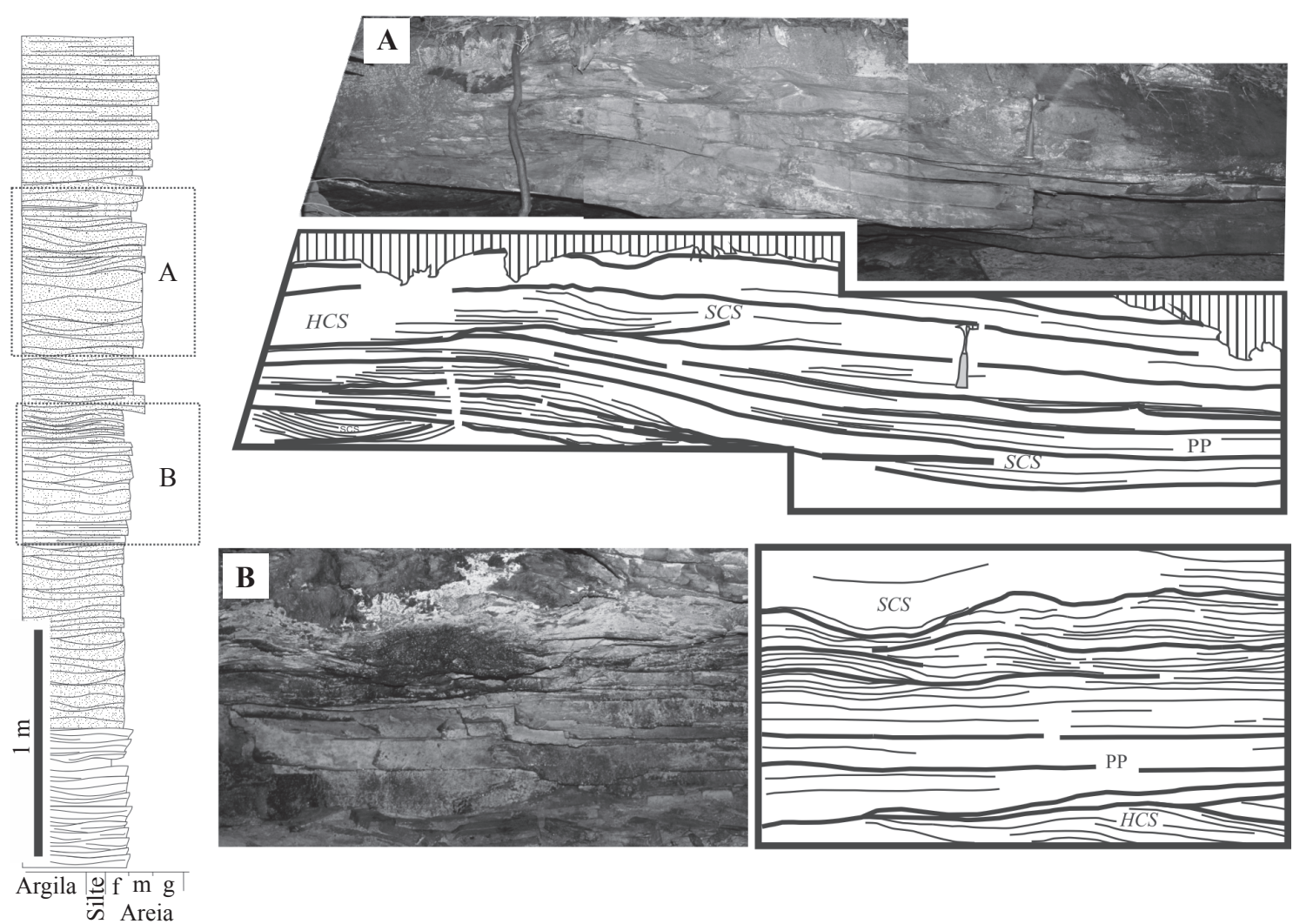

Figura 6 - Associação de frente deltaica (Af2): (A) vista panorâmica da estratificação cruzada hummocky (HCS) e swaley (SCS) em arenito fino; (B) detalhe de estratificação cruzada do tipo hummocky e swaley, arenito fino com laminações plano-paralelo $(P P)$.

selecionados com grãos de quartzo angulosos a subangulosos, pacotes amalgamados, lenticulares, estratificação cruzada acanalada (Fig. 7E). A fácies $A s$ representa arenitos médios a grossos, mal selecionados, com grãos de quartzo angulosos a subangulosos e acamamento sigmoidal.

Interpretação: a ocorrência de arenitos com granodecrescência ascendente, limitados na base por superfícies erosivas e, internamente, com estratos cruzados unidirecionais, indica depósitos de sand waves de ambiente de submaré. As estratificações cruzadas opostas contendo recobrimento de filmes argilosos nos foreset sugerem a ação de regimes de processos de maré. Intercalações de pelitos e siltitos com laminação incipiente ondulada indicam depósitos externos aos canais (overbank). Esses fatores são argumentos que atestam um contexto sedimentar em planície deltaica do tipo braided, onde os canais fluviais representam os ditributários alimentadores de deltas influenciados por maré e os sedimentos mais finos da planície.

\section{ASSOCIAÇÃO Af4 Domina na porção superior} da sucessão sedimentar (Fig. 4: Af4), com espessura $>10 \mathrm{~m}$, e é constituída de arenitos grossos a médios, mal a moderadamente selecionados, com grânulos de quartzo angulosos dispersos, subordinadamente, arenitos muito finos e pelitos intercalados. As camadas de arenitos possuem formas lenticulares amalgamadas, por vezes tabulares, lateralmente contínuas (>5 m), com espessuras que variam de $1 \mathrm{a} 2 \mathrm{~m}$ de espessura, tendo no topo marcas onduladas (Figs. 8A e B). Estratificação cruzada acanalada (fácies $A c$ ) de médio porte $(\sim 40-60 \mathrm{~cm}$ ) (Figs. $8 \mathrm{C}, \mathrm{E}$ e F) e tabular (fácies $A p$ ) de médio porte $(<30 \mathrm{~cm})$ gradam para estratificações cruzadas de baixo ângulo (fácies $A l$ ) e plano-paralela (fácies $A h$ ) (Fig. 8D). Marcas onduladas assimétricas e laminações cruzadas cavalgantes (fácies $A r$ ) ocorrem no topo dos pacotes de arenitos médios a finos. Acamamento heterolítico lenticular (siltito e pelito) exibe laminações plano-paralelas $(P l)$. Essa associação de fácies exibe um padrão de granodecrescência ascendente e adelgaçamento ascendente dos pacotes sedimentares.

Interpretação: arenitos grossos a médios, localmente conglomeráticos, dispostos na forma de camadas tabulares contínuas lateralmente, com ciclos de granodecrescência ascendente, sugerem depósitos de canais fluviais entrelaçados dominados 

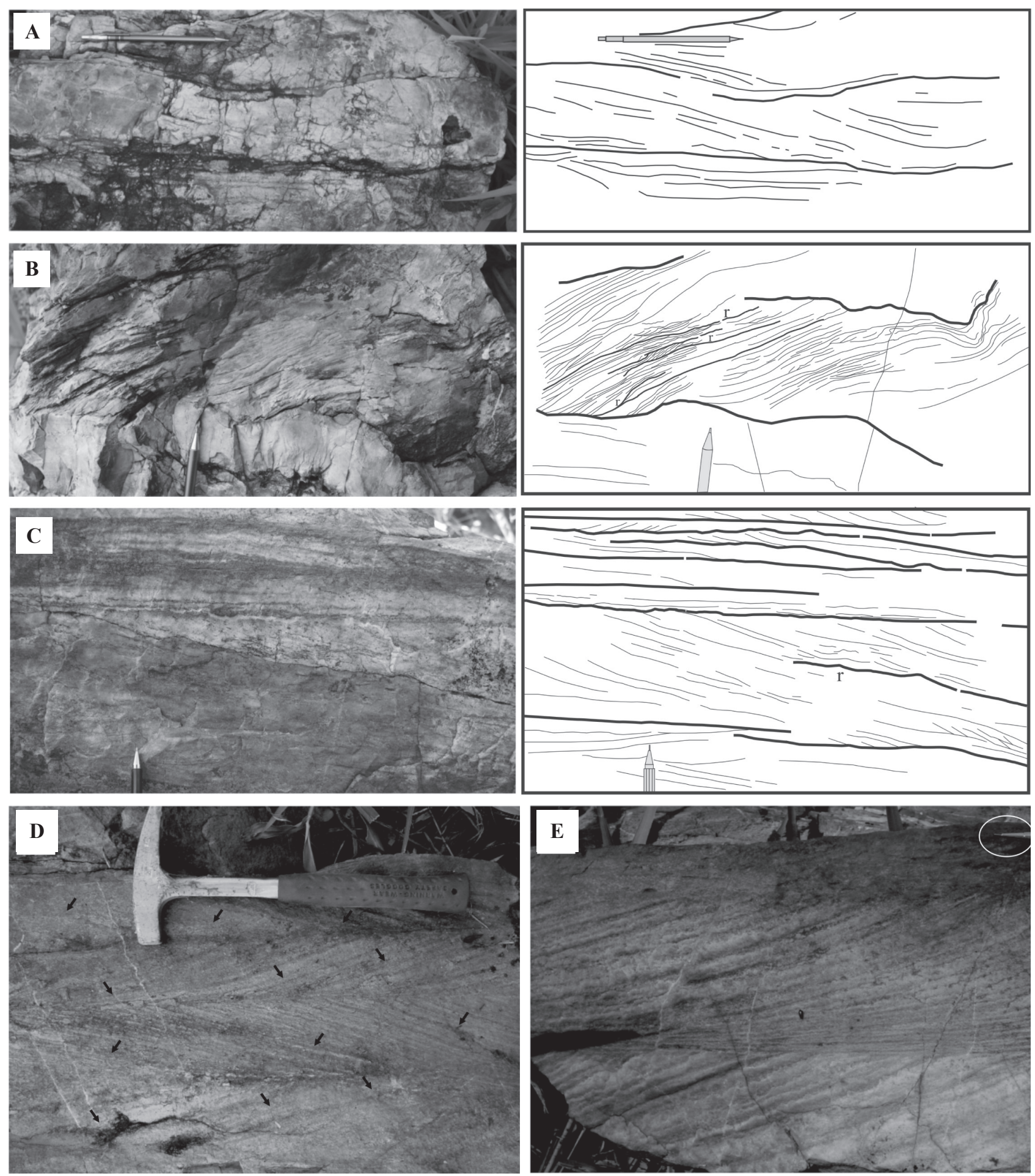

Figura 7 - Principais aspectos da Associação Af3: (A) arenito com topo e base ondulados e estratificação interna tabular; (B) estratificação tabular com superfícies de reativação; (C) laminações cruzadas cavalgantes com superficies de reativações; (D) estratificações cruzadas opostas (a espinha de peixe) com recobrimento argiloso (setas); e (E) estratificação cruzada tabular com terminação tangencial.

por carga de fundo (Miall 2006). A dinâmica dos processos fluviais é atestada pela presença dos depósitos de sedimentos na forma de barras fluviais do tipo 2D e 3D formadas ao longo do curso principal do sistema fluvial (fácies $A l, A r$ e $A s$ ), compondo um complexo de canais fluviais entrelaçados (Miall 2006).
O SISTEMA DEPOSICIONAL Com base na análise faciológica, descrição e correlação de afloramentos do Sinclinório de Rio Maria, as rochas sedimentares pré-cambrianas foram interpretadas na forma de uma única sucessão com predomínio de sedimentos marinhos na base que, gradativamente, são sucedidos por arenitos médios e grossos flúvio-deltáicos, 
caracterizando um padrão progradante (Fig. 9A). O sistema deposicional (Fig. 9B) inclui ambientes de barras distais-prodelta $(A f 1)$, frente deltaica-shoreface (Af2), planície deltaica-distributários $(A f 3)$ e fluvial entrelaçado (Af4), formados sobre terreno granito-greenstone, na borda leste do Bloco Rio Maria.

Ambiente deltaico É caracterizado por depósitos de barras distais-prodelta, barras de frente deltaica-shoreface superior e planície deltaica-canais distributários (Fig. 9). Os depósitos de barras distais-prodelta são lateralmente contínuos e incluem pelitos e arenitos finos que se interdigitam verticalmente aos sedimentos de barras de frente deltaica-shoreface superior, estes últimos caracterizados por corpos arenosos amalgamados, com estratificação cruzada hummocky-swaley de grande porte atribuída à ação de ondas de tempestades (Fig. 6). A presença de lobos com estratificação sigmoidal e a abundância de laminações cruzadas cavalgantes sugerem deposição em ambiente não confinado com elevado aporte sedimentar. $\mathrm{O}$ aumento da espessura dos pacotes sedimentares da base para o topo da seção (Fig. 4) é concorrente para a interpretação do aumento contínuo do espaço de acomodação. Marcas onduladas simétricas e assimétricas evidenciam processos sedimentares relacionados à ação contemporânea de recorrentes unidirecionais e oscilatórias atuantes na construção de barras de desembocadura. A planície deltaica compreende depósitos de preenchimento de canais distributários entrelaçados, representados por camadas amalgamadas que exibem contato basal erosivo e preenchimento de feições côncavas produzidas nas camadas subjacentes (Fig. 7A) ou tabulares com estratificação cruzada tabular (Fig. 7B). Laminações plano-paralelas e suavemente onduladas (Fig. 7C),
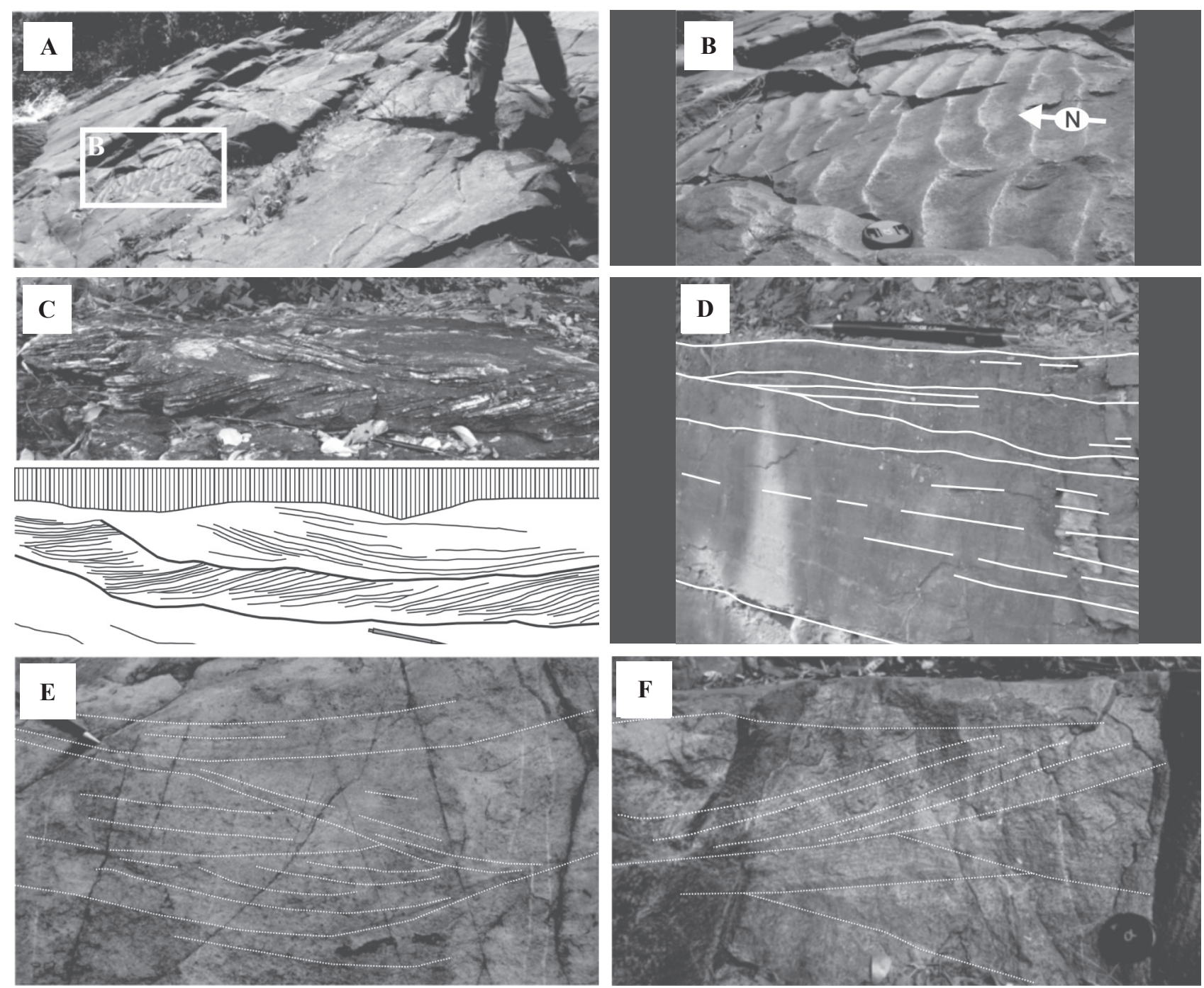

Figura 8 - Associação Af4: (A) pacotes tabulares de arenitos (fácies At); (B) detalhe das marcas onduladas assimétricas na superfície da camada (paleofluxo inferido para $N$ ); (C) arenito grosso com estratificação cruzada acanalada; (D) arenito médio a fino com laminação planar; e (E-F) estratificação cruzada de médio porte em arenito grosso. 
laminações onduladas simétricas e estratificação cruzada do tipo "espinha de peixe" (Figs. 7D e E) no topo de lobos arenosos indicam a ação de correntes de maré (De Raaf et al. 1977), consistentes com processos que ocorrem em ambiente de desembocadura de canais distributários de planície deltaicas.

Ambiente fluvial entrelaçado Ocorre no topo da sucessão sedimentar (Fig. 4) e é caracterizado pelo predomínio de sedimentos grossos (localmente conglomeráticos), mal selecionados, quartzosos que ocorrem imediatamente acima dos depósitos de ambiente deltaico. A prevalência de arenitos grossos, com estratificação cruzada acanalada de médio porte (Fig. 8E e F), com orientação unidirecional das estruturas, imbricamento de grãos de quartzo e, em alguns casos, com base das camadas fortemente erosiva atesta esse ambiente sedimentar. A ausência de bioturbação e de depósitos argilosos é consistente com o sistema fluvial entrelaçado (Miall 2006), especialmente no Pré-cambriano (Eriksson et al. 2004).

MODELO DEPOSICIONAL A interpretação dos padrões de sedimentação pré-cambriana é baseada nas litologias e estruturas sedimentares de seus análogos modernos (Altermann \& Corcoran 2002). Entretanto, a grande diferença entre os ambientes sedimentares pré-cambrianos e os modernos está relacionada ao fato de que as litofácies e os padrões de sedimentação clástica arqueanas se desenvoveram sob condições de variabilidade da taxa e intensidade do intemperismo, erosão, transporte e deposição distintos ainda pouco compreendidos (Donaldson et al. 2002, Eriksson et al. 2004). Segundo Ericksson \& Fedo (1994) os depósitos sedimentares siliciclásticos arquenos são dominados por depósitos de rios entrelaçados, deltaicos a marinho raso influenciado por maré e tempestade, em ambiente de plataforma continental (Ojakangas 1985, Lowe 1994, Eriksson et al. 1997). Segundo Eriksson et al. (2007), no registro estratigráfico pré-cambriano, é observado um aumento na frequência das sucessões sedimentares sinrifte e de plataforma continental entre 3,2 e 2,5 Ga. Talvez esse fato esteja relacionado aos sucessivos eventos de crescimento dos continentes no final do Arqueano. Por volta de 2,7 Ga e 2,2 - 1,8 Ga, a sedimentação global se processava em um momento de relativa estabilidade tectônica no mundo, acompanhada de um aumento do nível eustático. A fragmentação do supercontinente Kenorland por volta de 2,4-2,1 Ga (Aspler et al. 2001) promoveu a elevação do mar global a níveis muito altos. Consequentemente, em um novo momento de deriva continental (Windley 1995) em torno de 2,6 - 2,4 Ga, foram produzidos amplos mares pericratônicos que se constituíram em bacias de margem continental passiva, originando espessas

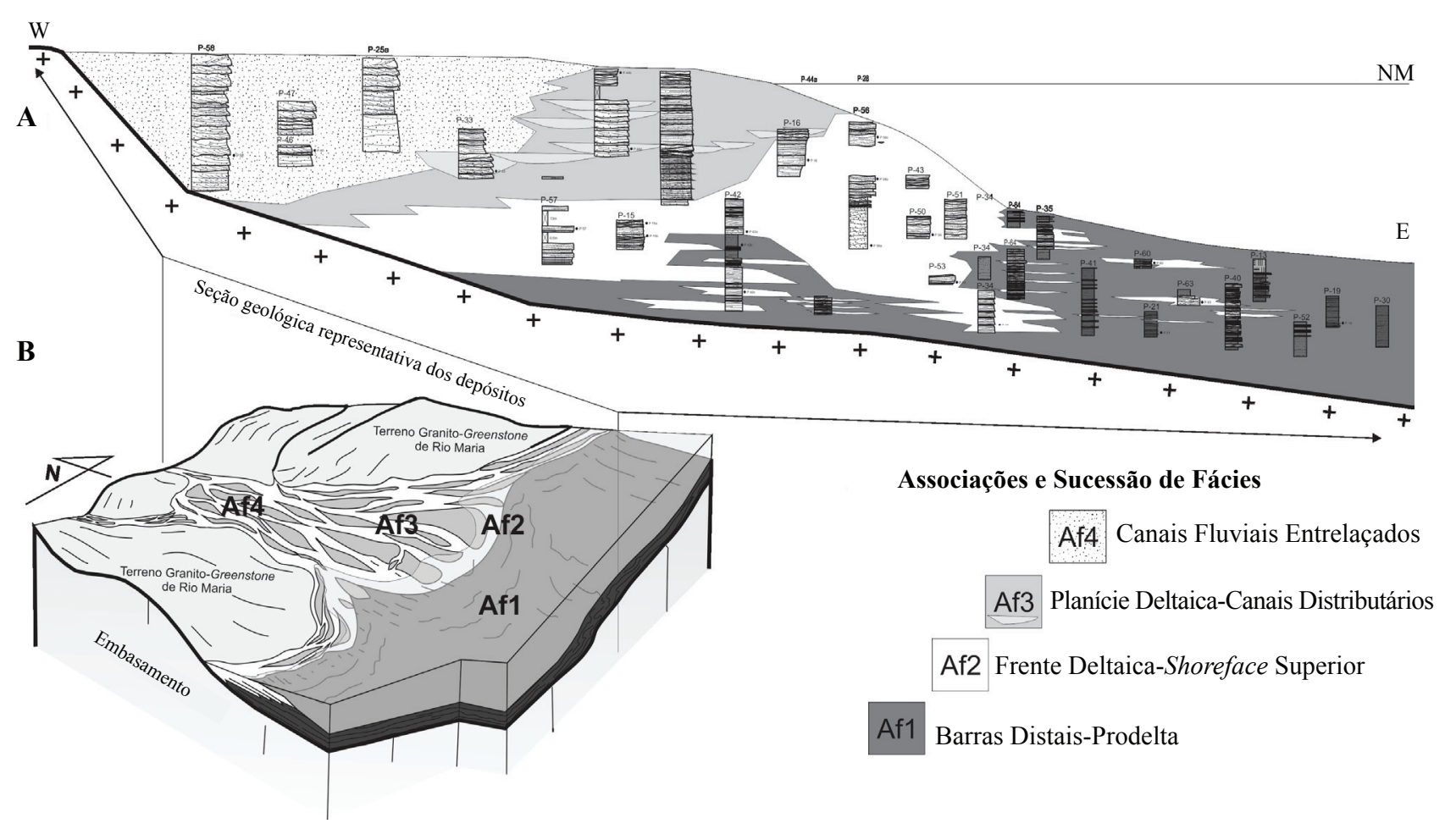

Figura 9 - (A) Seção composta da Formação Rio Maria elaborada a partir da correlação dos perfis estudados; (B) modelo deposicional flúvio-deltaico desenvolvido na borda leste do Terreno Granito-Greenstone de Rio Maria. 
sequências sedimentares de plataformas carbonáticas e formações ferríferas bandadas, principalmente, em torno de 2,5 Ga (Trendall \& Blockley 2004). Os mares epicontinentais constituíram-se em importantes espaços de acumulação para a deposição de espessas coberturas clásticas plataformais, cujos detritos foram trazidos, de regiões cratônicas estáveis adjacentes, por extensos sistemas de dispersão sedimentar. Esses depósitos, geralmente, apresentam elevada maturidade mineralógica e baixa maturidade textural, refletindo as características tectônicas da área-fonte (Dickinson 1985).

A disposição estratigráfica e geográfica da Formação Rio Maria no contexto geológico da Província Carajá, a análise das fácies e da sucessão de fácies indicam que o sistema deposicional flúvio-deltaico (Fig. 9B) foi implantado em uma bacia de margem continental, sobre terreno granito-greenstone. A sucessão sedimentar (Fig. 9A) é dominada por camadas de quartzo-arenito com geometria lobada (amalgamadas) com até $5 \mathrm{~m}$ de espessura, fortemente compactadas. Deltas entrelaçados (braided deltas) (Nemec \& Steel 1988) se formam onde os sistemas fluviais progradam diretamente em um corpo aquoso, com modificações variáveis e complexas dos depósitos aluviais na zona costeira com influência de tempestades e marés, formando discretas protuberâncias da linha de costa. Os deltas são classificados de acordo com os processos dominantes em: dominados por rios, por onda e por maré (Galloway 1985), ou até mesmo apresentam influência de todos esses processos, dependendo das condições geológicas vigentes.

Arenitos bem selecionados, com estratificação cruzada contendo superfícies de reativação, estratificações cruzadas bipolares $\left(180^{\circ}\right)$ (Fig. 7D), com recobrimento de filmes argilosos (drapes) atestam mudanças súbitas na dinâmica sedimentar, de curto período de tempo, nas formas de leito provocadas pela ação de correntes de maré, em ambiente de planície deltaica. Arenitos finos, bem selecionados em ambiente de frente deltaica-shoreface, com estratificação cruzada do tipo hummocky e swaley de grande porte, representam depósitos de tempestades, caracterizados por relevo muito suave e laminação de baixo ângulo $\left(<10-15^{\circ}\right)$, com a parte convexa do HCS voltada para cima e côncava da swaley para baixo (Fig. 6). As laminações plano-paralelas (P), passando para estratificação hummocky e laminações cruzadas (ripples: $\mathrm{r}$ ) em arenito muito fino com laminações quasi-planares (Figs. 6A e B), indicam ação de fluxos combinados associados a ondas de tempestades (Arnott \& Southard 1990, Tucker 2003). Laminações e acamamentos convolutos (Figs. 5B e C) indicam processo de deformação sin-sedimentar por fluidização nos depósitos de frente deltaica e/ou sobrecarga nos sedimentos mais finos no prodelta. Dessa forma, admite-se que os depósitos sedimentares da Formação Rio Maria representam eventos multiepisódicos que combinam processos trativos unidirecionais com dinâmica de alta energia, em que o alto grau de amalgamação dos corpos arenosos representa constantes avulsões dos canais fluviais e a ausência de depósitos de planícies de inundação indica forte dinâmica do ambiente, uma vez que no Pré-cambriano a ausência de vegetação favorecia a não preservação desses tipos de depósitos (Eriksson et al. 2004).

\section{COMPOSIÇÃO DOS ARENITOS E AMBIENTE} TECTÔNICO Os arenitos da Formação Rio Maria possuem granulometria que varia de fina, média a grossa, sendo constituídos basicamente de quartzo (Q: $62-100 \%$ ) e, subordinadamente, feldspato $(F:<6 \%)$, fragmentos líticos $(L: 1-6 \%)$, minerais acessórios e cimento $(C)$. Os resultados da análise petrográfica encontram-se listados na Tabela 1.

As composições modais do arcabouço detrítico plotam no campo do quartzo-arenito, com exceção de duas amostras (ambiente fluvial) que caem nos campos do litarenito e na interface do campo do subarcóseo-quartzarenito (Fig. 10A). Os grãos do arcabouço exibem contatos longo a suturado, eventualmente, pontuais. A porosidade intergranular (primária) é praticamente inexistente e a porosidade secundária é mais frequente. Em algumas amostras, a matriz $(M)$ é argilosa e representa cerca de $1-10 \%$ do arcabouço. O cimento de sílica ocorre na forma de crescimento secundário sintaxial e epitaxial, às vezes facilmente reconhecido pela presença de filmes de óxido de ferro preservado no contato grão-cimento (cutans). As evidências texturais e mineralógicas desses arenitos envolvem processos dos regimes eo- e mesodiagenéticos.

O quartzo ocorre como grãos monocristalinos ( $Q m$ : predominante) e policristalinos $(Q p$ : mais abundantes nos arenitos grossos), geralmente angulosos a subangulosos, com baixa esfericidade e exibindo extinção ondulante. Grãos $Q m$ exibem forma angulosa a subangulosa, às vezes bem arredondada, equidimensionais, com extinção normal a levemente ondulante (Fig. 10B e C), além de trilhas de inclusões minerais 
Tabela - Composição modal dos arenitos da Formação Rio Maria. Valores dos componentes volumétricos do arcabouço estão em porcentagem.

\begin{tabular}{|c|c|c|c|c|c|c|c|c|c|c|c|c|}
\hline Amostra & Granulometria & $\mathrm{Q}$ & $\mathrm{F}$ & $\mathrm{L}$ & Qm & Qp & M & $\mathrm{Cm}$ & Total & $\mathrm{Qm} / \mathrm{Qp}$ & & \\
\hline P8a & Grossa & 62 & 4 & 34 & 65 & 35 & 0 & 0 & 600 & 1,9 & \multirow{18}{*}{ 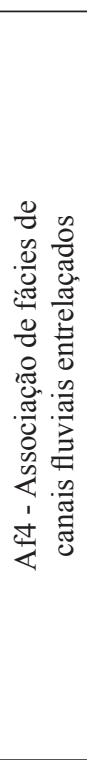 } & \\
\hline $\mathrm{P} 8 \mathrm{~b}$ & Média & 100 & 0 & 0 & 90 & 10 & 0 & 15 & 600 & 9 & & \\
\hline $\mathrm{P} 8 \mathrm{c}$ & Média & 100 & 0 & 0 & 98 & 2 & 0 & 30 & 600 & 49 & & \\
\hline $\mathrm{P} 2 \mathrm{~F}$ & Média/Grossa & 100 & 0 & 0 & 83 & 17 & 1 & 0 & 600 & 4,9 & & \\
\hline P1B & Média & 100 & 0 & 0 & 85 & 15 & 8 & 0 & 600 & 5,7 & & \\
\hline $\mathrm{P} 2 \mathrm{~A}$ & Fina/Média & 100 & 0 & 0 & 91 & 9 & 0 & 0 & 600 & 10,1 & & \\
\hline P2B & Grossa & 100 & 0 & 0 & 79 & 21 & 10 & 0 & 600 & 3,8 & & \\
\hline $\mathrm{P} 2 \mathrm{C}$ & Grossa & 100 & 0 & 0 & 76 & 24 & 0 & 5 & 600 & 3,2 & & \\
\hline P2D & Média & 100 & 10 & 0 & 88 & 12 & 0 & 0 & 600 & 7,3 & & \\
\hline P2E & Média & 100 & 0 & 0 & 90 & 10 & 0 & 0 & 600 & 9 & & \\
\hline P1A & Média & 100 & 0 & 0 & 82 & 18 & 8 & 0 & 600 & 4,6 & & \\
\hline P17 & Grossa & 100 & 0 & 0 & 74 & 26 & 0 & 2 & 600 & 2,8 & & \\
\hline $\mathrm{P} 1 \mathrm{C}$ & Média & 100 & 0 & 0 & 92 & 8 & 0 & 5 & 600 & 11,5 & & \\
\hline P23 & Grossa & 100 & 0 & 0 & 56 & 44 & 0 & 0 & 600 & 1,3 & & \\
\hline P01 & Grossa & 100 & 0 & 0 & 0 & 0 & 0 & 0 & 600 & 0 & & \\
\hline P02 & Grossa & 100 & 0 & 0 & 0 & 100 & 0 & 0 & 600 & 0 & & \\
\hline P16 & Grossa & 100 & 0 & 0 & 98 & 2 & 0 & 15 & 600 & 49 & & \\
\hline $\mathrm{P} 25$ & Grossa & 100 & 0 & 0 & 95 & 5 & 0 & 20 & 600 & 19 & & \\
\hline P06 & Grossa & 100 & 0 & 0 & 86 & 14 & 0 & 2 & 600 & 6,1 & \multirow{14}{*}{ 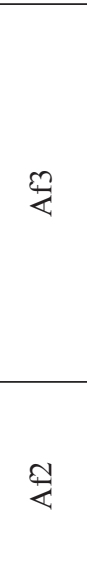 } & \multirow{14}{*}{ 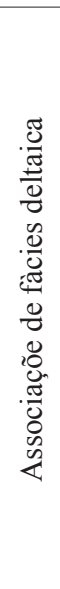 } \\
\hline P07 & Média & 100 & 0 & 0 & 96 & 4 & 0 & 5 & 600 & 24 & & \\
\hline P08 & Média & 100 & 0 & 0 & 88 & 12 & 0 & 8 & 600 & 7,3 & & \\
\hline P11 & Média & 100 & 0 & 0 & 90 & 10 & 0 & 3 & 600 & 9 & & \\
\hline P15a & Média & 100 & 0 & 0 & 95 & 5 & 0 & 0 & 600 & 19 & & \\
\hline P45 & Grossa & 92 & 3 & 5 & 97 & 3 & 0 & 8 & 600 & 32,3 & & \\
\hline P46 & Grossa & 96 & 0 & 4 & 94 & 6 & 0 & 10 & 600 & 15,7 & & \\
\hline P47 & Grossa & 98 & 1 & 1 & 97 & 2 & 0 & 5 & 600 & 48,5 & & \\
\hline P59 & Grossa & 93 & 1 & 6 & 84 & 14 & 0 & 0 & 600 & 6 & & \\
\hline P61 & Grossa & 92 & 6 & 2 & 82 & 13 & 0 & 0 & 600 & 6,3 & & \\
\hline P43 & Média & 100 & 0 & 0 & 0 & 0 & 0 & 10 & 600 & 0 & & \\
\hline P53 & Média & 100 & 0 & 0 & 96 & 3 & 0 & 15 & 600 & 32 & & \\
\hline P54 & Fina/Média & 100 & 0 & 0 & 94 & 5 & 0 & 5 & 600 & 18,8 & & \\
\hline P56b & Fina/Média & 97 & 0 & 3 & 97 & 2 & 0 & 0 & 600 & 48,5 & & \\
\hline
\end{tabular}

Q: quartzo; F: feldspato; L: fragmentos líticos; Qm: quartzo monocristalino; Qp: quartzo policristalino; M: matriz; Cm: cimento de sílica.

e fluidas. Os grãos $Q p$ são constituídos de cristais com contatos suturados (Fig. 10B). Grãos de feldspatos têm formas arredondadas, sendo constituídos basicamente de ortoclásio, com ocorrências esporádicas de plagioclásio microclínio (Fig. 10C). Feições de corrosão e/ou dissolução intraestratal foram frequentemente observadas nos grãos do arcabouço.

Fragmentos de rochas metamórficos (metapelitos e metarenitos) e sedimentares (arenitos finos e chert) ocorrem apenas nos arenitos com granulação grossa, possuindo formas tabulares angulosas e feições de deformação intraestratal (Fig. 10D). Grãos de chert têm forma arredondada e alongada e textura microcristalina. Os principais minerais acessórios nesses arenitos incluem zircão, turmalina, rutilo, muscovita e anfibólio. A muscovita, mais frequente nos arenitos finos, exibe deformação intergranular.
A matriz (Figs. 10B e C), embora pouco abundante, é constituída de minerais argilosos (caulinita, illita e clorita), contendo esparsos grãos de quartzo monocristalinos, angulosos, além de lamelas de muscovita identificadas segundo as suas propriedades óticas. Os arenitos da Formação Rio Maria são caracterizados pela abundância de quartzo, ocorrência limitada de grãos de feldspatos e líticos, sendo assim mineralogicamente supermaturos, com altas razões $Q m / Q p$, em que o quartzo monocristalino $(\mathrm{Qm})$ perfaz mais de $95 \%$. A composição modal dos constituintes detríticos dos arenitos se distribui no campo da proveniência de blocos continentais em ambiente de cráton interior (Fig. 11). Blocos continentais são regiões tectonicamente consolidadas que incluem cinturões orogênicos antigos amalgamados que foram erodidos profundamente, desenvolvendo relevo plano, 

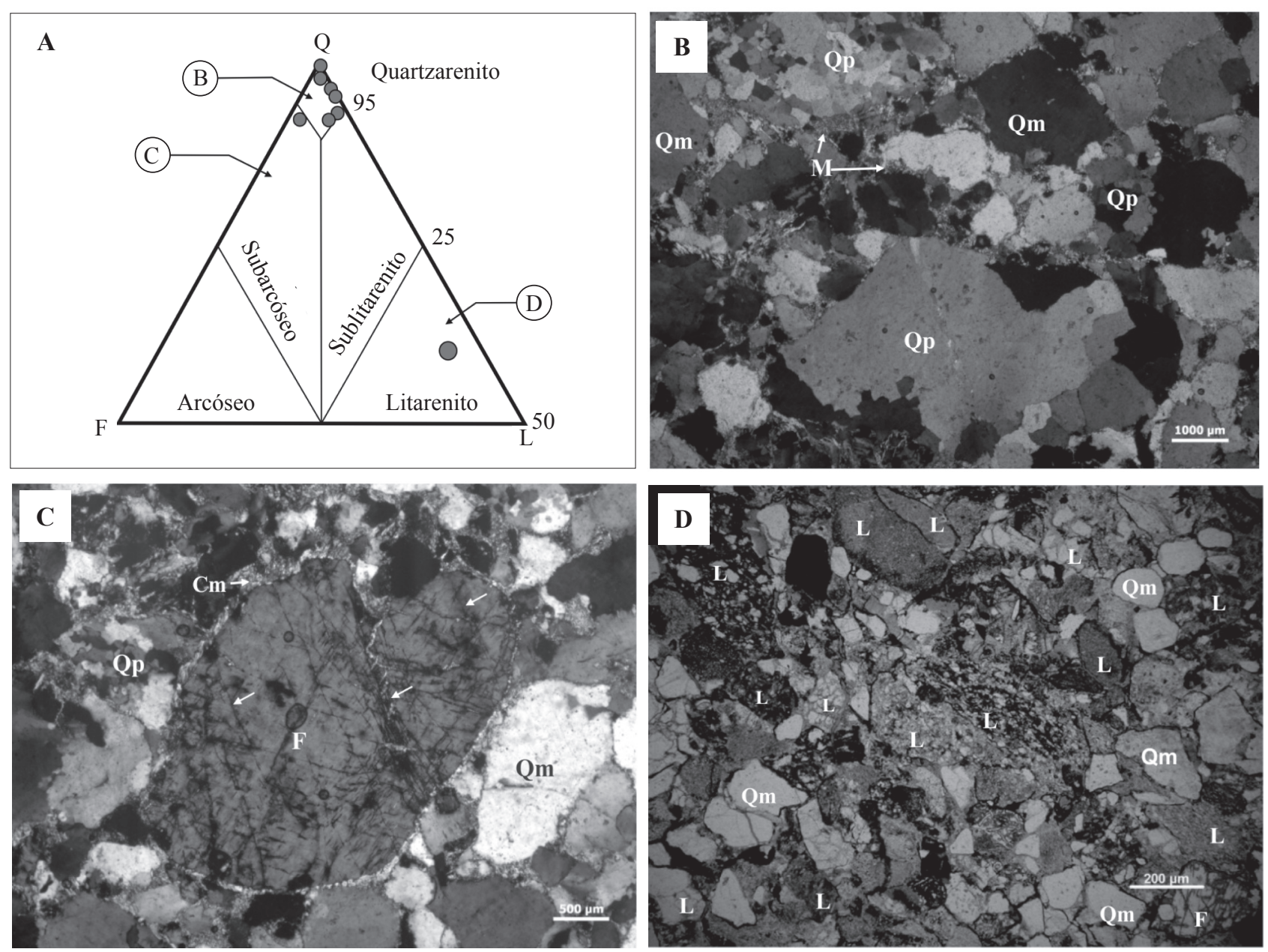

Figura 10 - (A) Diagrama ternário (Dott 1964) para a classificação dos arenitos da Formação Rio Maria; micrografias: (B) quartzarenito grosso com destaque para os grãos de quartzo policristalinos ( $Q p)$, monocristalinos $(\mathrm{Qm})$ e matriz $(M)$; $(C)$ subarcóseo grosso com feldspato $(F)$ arredondado coroado por franjas de illita e fraturas, associado com caulinita na forma de cimento (Cm); e (D) litarenito com abundantes fragmentos de rochas sedimentares e metassedimentares $(L)$.

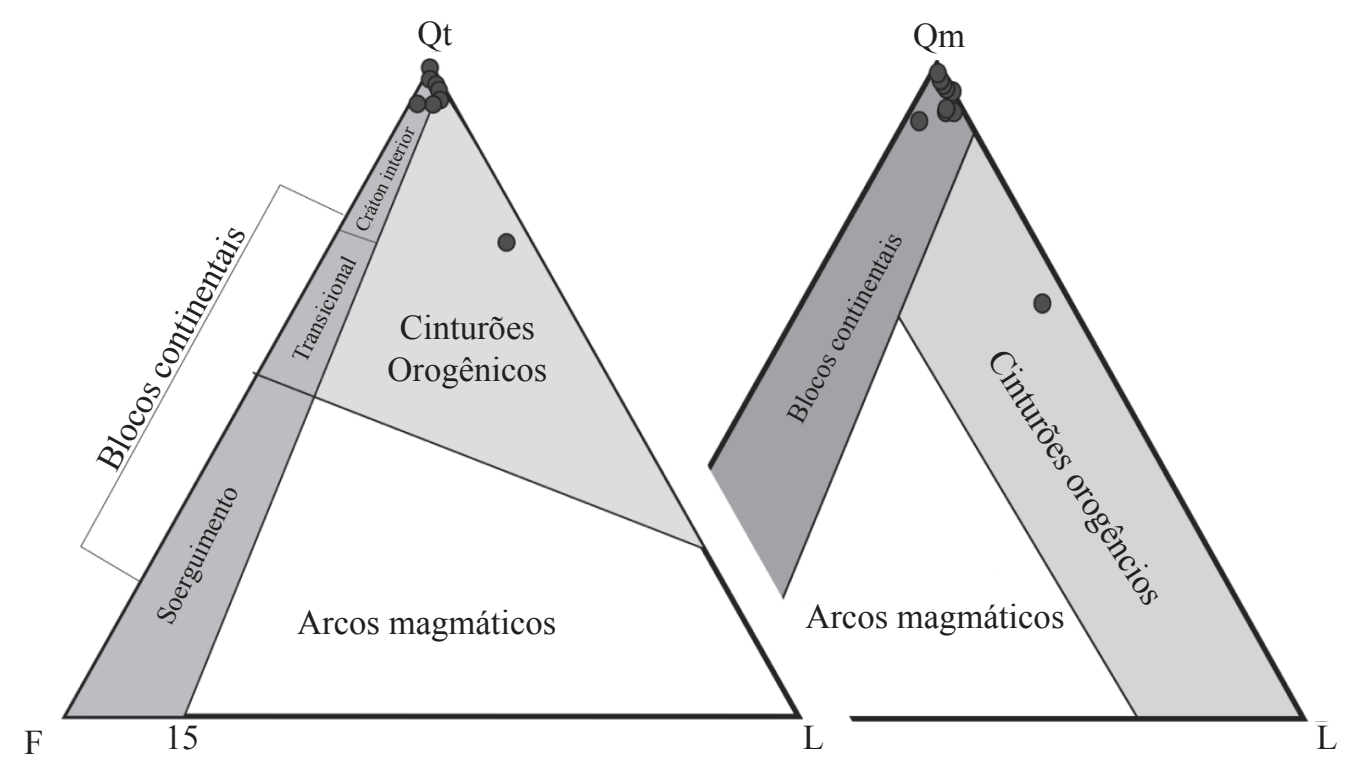

Figura 11 - Relação da composição modal dos arenitos da Formação Rio Maria e sua proveniência nos diagramas de Dickinson (1985). 
além de corpos graníticos anorogênicos. Nesse tipo de contexto tectônico, os sedimentos têm maior tempo de residência na área-fonte, ficando mais tempo expostos ao intemperismo antes de serem transportados até extensas sucessões sedimentares plataformais no interior do continente ou em margens continentais passivas. As características mineralógicas e texturais observadas nos arenitos da Formação Rio Maria representam esses fatores e processos geológicos relacionados à proveniência e aos mecanismos de sedimentação dos depósitos sedimentares.

\section{CONCLUSÕES A Formação Rio Maria com-} preende um sistema deposicional flúvio-deltaico desenvolvido em uma bacia de mar epicontinental formada na borda leste da Província Carajás, que inclui o terreno granito-greenstone de Rio Maria. A sucessão das fácies arenitos e pelitos caracteriza progradação do ambiente flúvio-deltaico sobre ambiente marinho raso plataformal, atestando o recuo da linha de costa (regressão).

Arenitos finos com estratificação cruzada tipo hummocky e swaley de grande porte evidenciam ondas de tempestades durante a acumulação desses depósitos, e estratificação do tipo espinha de peixe com recobrimento argiloso atestam ação de processos de maré na planície deltaica.

A sucessão sedimentar pode ser interpretada na forma dois membros: Cachoerinha (inferior) e São Roque (superior), que compõem formação, aqui nominada, de Formação Rio Maria, em homenagem ao rio homônimo que corta área de exposição dessas rochas.

Os arenitos indicam fontes de blocos continentais (cráton interior) que incluem rochas-fonte metamórficas (baixo grau), graníticas e sedimentares (reciclagem). As maturidades composicional e textural dos sedimentos (quartzarenito), a ausência de uma sedimentação mais grossa e predomínio de sedimentos finos, bem como o desenvolvimento de uma assembleia de minerais pesados ultraestáveis, indicam longo período de estabilidade tectônica.

A Formação Rio Maria, na área estudada, encontra-se confinada em um sinclinório aberto de orientação W-E com deformações rúpteis-dúcteis brasilianas com a atual configuração estrutural, que se destaca no cenário geológico do terreno granito-greenstone de Rio Maria.

AGRADECIMENTOS Os autores agradecem ao CNPq (576541/2008-7/CT-Mineral) e à FAPESPA (Universal) pelo aporte financeiro, à Faculdade de Geologia da UFPA (Campus de Marabá) pelo uso do Laboratório de Petrografia, e, em especial, à colaboração do Prof. Roberto Vizeu Pinheiro pelo apoio nas etapas de campo. Os agradecimentos são extensivos aos revisores da RBG que contribuíram com a interpretação e discussão dos resultados.

\section{Referências}

Almeida F.F.M. 1967. Origem e evolução da plataforma brasileira. Rio de Janeiro, DNPM/DGM, 36 p, (Boletim 241).

Almeida F.F.M. 1978. A evolução dos crátons Amazônico e São Francisco comparada com seus homólogos do hemisfério norte. In: SBG, Congresso Brasileiro de Geologia, 30, Recife, Anais, 6, p. 2393-2407.

Altermann W. \& Corcoran P.L. 2002. Precambrian sedimentary environments: a modern approach to ancient depositional systems (eds.). Oxford, Blackwell, Special Publication, $450 \mathrm{p}$.

Aspler L.B., Wisotzec I.E., Chiarenzelli J.R., Cousens B.L., McNicoll V.J., Davis W.J. 2001. Paleoproterozoic intracratonic basin processes, from breakup of Kenorland to assembly of Laurentia: Hurwitz Basin, Nunavut, Canada. Sedimentary Geology, 141-142:287-318.

Arnott R. W. \& Southard J. B. 1990. Exploratory flow-duct experiments on combined-flow bed configurations, and some implications for interpreting storm-event stratification. Journal of Sedimentary Petrology, 60:211-219.

Avelar V.G. 1996. Geocronologia Pb-Pb por evaporação em monocristal de zircão do magmatismo da região de Tucumã, SE do Estado do Pará, Amazônia Oriental. Dissertação de Mestrado, Instituto de Geociências, Universidade Federal do Pará, Belém, 149 p.

Barbosa O, Ramos J.R.A., Gomes F.A., Helmont R. 1966. Geologia estratigráfica, estrutural e econômica da área do "Projeto Araguaia". Monografia da DGM, Rio de Janeiro, $94 \mathrm{p}$.

Catuneanu O. 2006. Principles of sequence Stratigraphy. Oxford, Elsevier, Kidlington, 375 p.

Cheel R.J. \& Leckie D.A. 1993. Hummocky crossstratification. In: Wright V. P. (ed.) Sedimentology Review/1. Cambridge, Blackwell Scientific Publication, p. 103-122.

Cordeiro A.A.C. 1982. Geologia preliminar da região 
de Andorinhas. In: SBG, Simpósio de Geologia da Amazônia. 1, p. 45-49.

Cordeiro A.A. C. \& Saueressig R. 1980. Serra das Andorinhas: geologia e principais ocorrências de ouro. In: SBG, Congresso Brasileiro de Geologia, 31, Camborfú, p. 344.

CPRM - Serviço Geológico do Brasil. 2008. Geologia e Recursos Minerais do Estado do Pará. Escala 1:1.000.000. Fortaleza, CPRM, PRODEEM, CD Rom.

Cunha B.C.C., Santos D.B., Prado P. 1984. Contribuição ao estudo da estratigrafia da região dos Gradaús com ênfase no Grupo Rio Fresco. In: SBG Congresso Brasileiro de Geologia, 33, Rio de Janeiro, Anais, 2:873-885.

Dall'Agnol R., Lafon J.M., Macambira M.J.B. 1994. Proterozoic anorogenic magmatism in the Central Amazonian Province: geochronological, petrological and geochemical aspects. Mineralogy and Petrology 50:113-138.

De Raaf J.F.M., Boersma J.R., Van Gelder A. 1977. Wavegenerated structures and sequences from a shallow marine succession, Lower Carboniferous, County Cork, Ireland. Sedimentology, 24:451-483.

Dias G.S., Macambira M.J.B., Dall'Agnol R., Soares A.D.V., Barros C.E. 1996. Datação de zircões de sill de metagabro: comprovação da idade arqueana da Formação Águas Claras, Carajás - Pará. In: SBG Simpósio de Geologia da Amazônia, 5, Resumos Expadidos, Belém, p. 376-379.

Dickinson W.R. 1985. Interpreting provenance relations from detrital modes of sandstones. In: Zuffa G.G. (ed.) Provenance of Arenites. NATO ASI Series C 148, Reidel, Dordrecht, p. 333-361.

DOCEGEO 1988. Revisão litoestratigráfica da Província Mineral de Carajás. In: SBG Congresso Brasileiro de Geologia, 25, Anais, p. 11-56.

Donaldson J.A., Eriksson P.G., Altermann. W. 2002. Actualistic versus non-actualistic conditions in the Precambrian sedimentary record: reappraisal of an enduring discussion. International Association of Sedimentologists, Special Publication, 33:3-13.

Dott R.H. 1964. Wacke, greywacke and matrix-what approach to immature sandstone classification. Journal of Sedimentary Petrology 34:625-632.

Duke W.L., Arnott R.W.C., Cheel R.J. 1991. Shelf sandstone and hummocky cross-stratification: new insights on a storm debate. Geology, 19:625-628.

Erikson K.A., Fedo C.M. 1994. ArcheanSynrift and Stable-shelf Sedimentary Successions. In: Condie K.C. (ed.). Archean Crustal Evolution: Developments in Precambrian Geology, vol. 11, p. 171-204.

Eriksson K.A., Krapez B., Fralick P.W. 1997. Sedimentological aspects of Greenstone Belts. In: Wit M.J. \& Ashwal L.D. (eds.). Oxford, Oxford Science Publications, p. 291-293.

Eriksson P.G., Altermann W., Nelson D.R., Mueller W., Catuneanu O. (eds.). 2004. The Precambrian Earth:
Tempos and Events. In: Developments in Precambrian Geology, vol. 12, Amsterdam, Elsevier, 941 p.

Eriksson P.G., Porada H., Banerjee S., Bouougri E., Sarkar S., Bumby A.J. 2007. Matdestruction features. In: Schieber J., Bose P.K., Eriksson P.G., Banerjee S., Sarkar S., Altermann W., Catuneanu O. (eds.). Atlas of microbial mat features preserved within the siliciclastic rock record. Elsevier Atlas in Geology vol. 2, Amsterdam, Elsevier, p. 76-105.

Faraco M.T.L. 2004b. Folha SB.22 - Araguaia. In: Schobbenhaus C. (Ed.). Carta geológica do Brasil ao milionésimo: Sistema de informações geográficasSIG. Programa Geologia do Brasil. Brasília, CPRM. CD-Rom.

Ferreira A.T.R., Almeida J.A.C., Dall'Agnol R. 2008. Geologia e petrologia magnética dos diques da área de Bannach, Terreno Granito-Greenstone de Rio Maria, sudeste do Pará. In: SBG, Simp. Vulc. e Amb. Assoc., Foz do Iguaçu.

Galloway W.E. 1985. Meandering streams-modern and ancient: recognition of fluvial depositional systems and their resource potential. Society of Economic Paleontology and Mineralogy Short Course 19:145-166.

Huhn S.R.B., Santos A.B.S., Amaral A.F., Ledsham E.J., Gouveia J.L., Martins L.B.P., Montalvão R.M.G., Costa V.G. 1988. O Terreno GranitoGreenstone da região de Rio Maria - Sul do Pará. In: SBG, Congresso Brasileiro de Geologia, 35, Belém, Anais, p. 1438-1453.

Leckie D.A. \& Walker R.G. 1982. Storm- and tidedominated shorelines in cretaceous Moosebar Loweer Gates Interval-Outcrop equivalents of deep basin gas trap in Western Canada. American Association of Petrolium Geologists, Bulletin, 66(2):138-157.

Leite A.A.S., Dall'Agnol R., Macambira M.J.B., Althoff F.J. 2004. Geologia e geocronologia dos granitóides arqueanos da região de Xinguara-PA e suas implicações na evolução do terreno granito-greenstone de Rio Maria, Cráton Amazônico. Revista Brasileira de Geociências, 34(4):447-458.

Lowe D.R. 1994. Archean greenstone-related sedimentary rocks. In: Condie K.C (ed.). Archean Crustal Evolution Developments in Precambrian Geology, vol. 11, Amsterdam, Elsevier, p. 121-169.

Macambira M.J.B. \& Lancelot J. 1991. Em busca do embasamento arqueano da região de Rio Maria, sudeste do Estado do Pará. In: SBG, Simpósio de Geologia da Amazônia, 3, Belém, p. 49-58.

Macambira M.J.B. 1992. Chronologie U-Pb, Rb-Sr, K-Ar ET croissance de La croûte continentale dans I'Amazonie Du sud-est; exemple de La région de RioMaria, Província de Carajás, Brésil. Doctor Thesis, University of Montpellier II, Montpellier, $212 \mathrm{p}$.

Marinho P.A.C. 1977. Projeto Carvão no Rio Fresco. Belém, CPRM, 126 p.

Miall A.D. 1978. Lithofacies types and vertical profile models in braided- rivers deposits: a summary. In: 
Miall A.D. (ed.) Fluvial Sedimentology. Calgary, Canadian Society of Petroleum Geologists, Memoir 5, p. 597-604.

Miall A.D. (ed.). 2006. The Geology of Fluvial Deposits: sedimentary facies, basin analysis and petroleum geology. New York, Springer, 582 p.

Mougeot R., Respaut J.P., Briqueu L., Ledru P., Macambira M.J.B., Huhn S.B. 1996. Geochronological constrains for the age of the Águas Claras Formation (Carajás Province, Para, Brazil). In: SBG, Congresso Brasileiro de Geologia, 39, Camboriu, Anais, 6:579-581.

Moura C.A.V. \& Gaudette H.E. 1999. Zircon age of the Basement Orthogneisses from the northern segment of the Araguaia Belt, Brazil. In: Sinha A.K. (ed.) Basemen Tectonic 13, Holanda, Kluwer Academic Publishers, p. 155-178.

Nemec W. \& Steel R.J. 1984. Alluvial and coastal conglomerates: their significant features and some comments on gravelly mass-flow deposits. In: Koster E.H. \& Steel R.J. (eds.) Sedimentology of gravel and conglomerates. Calgary, Canadian Society of Petroleum Geologists (Memoir 10), p. 1-31.

Ojakangas R.W.1985. Review ofArchean clastic sedimentation, Canadian Shield: major felsic volcanic contributions to turbidite and alluvial fan-fluvial facies associations. In: Ayres P.C., Thurston K.D., Weber W. (eds.) Evolution of Archean Supracrustal Sequences. Geological Association of Canada, Special Publication 28:23-48.

Oliveira D.C. 2006. Modelos de evolução e colocação dos Granitos Paleoproterozóicos da Suíte Jamon, SE do Cráton Amazônico. Tese de Doutorado, Instituto de Geociências, Universidade Federal do Pará, Belém, 186 p.

Oliveira A.I. 1928. Reconhecimento geológico do Rio Xingu, Estado do Pará. Boletim do Serviço Geológico Mineralógico, 29, Rio de Janeiro, p. 3-22.

Santos A. \& Pena Filho J.I.C. 2000. Xinguara: Folha SB.22- Z-C. Estado do Pará, escala 1:250.000. Brasília. CD-Rom.

Santos A.R., Paradella W.R., Veneziani P. 2003. Avaliação da Estereoscopia SAR (StandardRADARSA T-1) e Híbrida (Standard- RADARSA
T-1 \& TM-Landsat 5) em mapeamento geológico na Província Mineral de Carajás. Revista Brasileira de Geociências 33:153-160.

Sardinha A.S. 2002. Geologia, geoquímica e geocronologia do Granito Serra do Rabo, Província Mineral de Carajás. Dissertação de Mestrado, Instituto de Geociências, Universidade Federal do Pará, Belém, 118 p.

Silva G.G., Lima M.J.C., Andrade A.R.F., Issler R.S., Guimarães G. 1974. Geologia das Folhas SB-22 Araguaia e parte da SC-22 Tocantins. In: Projeto RADAM-BRASIL, Levantamento de Recursos Naturais, Rio de Janeiro, 143 p.

Snedden J.W. \& Nummedal D. 1991. Origin and geometry of storm-deposited sand beds in modern sediments of the Texas continental shelf. In: Swift D.J.P., Tillman R.W., Oertel G.F., Thorne J.A. (eds.) Shelf Sand and Sandstone Bodies: Geometry, Facies and Sequence Stratigraphy. International Association Sedimentologists, Special Publication, 14:283-308.

Tassinari C.C.G. \& Macambira M.J.B. 1999. Geochronological Provinces of the Amazonian Craton. Episodes, 22(3):174-182.

Trendall A.F. \& Blockley J.G. 2004. Precambrian iron-formations. In: Eriksson P.G., Altermann W., Nelson D.R., Muller W.U., Catuneanu O. (eds.) The Precambrian Earth: temps and events. Developments in Precambrian Geology, vol. 12. Amsterdam, Elsevier, p. 403-421.

Tucker M.E. 2003. Sedimentary rocks in the field: the geological field guide series, 3rd ed. Chichester, Wiley, $234 \mathrm{p}$.

Walker R.G. \& Plint A.G. 1992. Wave and storm dominated shallow marine system. In: Walker R.G. \& James N.P. (eds.) Facies models: response to sea level change. Geological Association of Canada, p. 9-238.

Windley B. F. (ed.). 1995. The evolving continents. Chichester, John Wiley \& Sons, 526 p.

Manuscrito ID 24974

Recebido em: 11/11/2011

Aprovado em: 28/06/2012 